\title{
Human Immunodeficiency Virus (HIV) Masquerading as Myopathy and Rhabdomyolysis
}

\author{
Kushal Ranabhat $^{1}$, Smit Deliwala ${ }^{1}$, MurtazaShabbir Hussain ${ }^{1}$, Tarek Haykal ${ }^{2}$, Ghassan Bachuwa ${ }^{1}$ \\ 1. Internal Medicine, Michigan State University at Hurley Medical Center, Flint, USA 2. Division of Oncology, \\ Department of Internal Medicine, Duke University, Durham, USA
}

Corresponding author: Smit Deliwala, deliwal1@msu.edu

\begin{abstract}
Human immunodeficiency virus (HIV) characteristically presents as a mononucleosis-like prodrome; rhabdomyolysis as a sole manifestation remains a rare finding from infection to seroconversion. A young male with a vague sexual history presented with myopathy progressing rapidly to rhabdomyolysis and renal failure. Acute HIV rarely presents with classic features, and rhabdomyolysis seems to manifest more in younger patients. Our case also demonstrates the importance of keeping a strong suspicion for HIV in the right setting despite false-negative results in the pre-seroconversion phase. The variability in HIV presentation and stigma of sexual history taking represents a diagnostic challenge. The astute clinician must be privy to these peculiarities to formulate a prompt diagnosis.
\end{abstract}

Categories: Internal Medicine, Infectious Disease, Rheumatology

Keywords: hiv, rhabdomyolysis, myopathy, creatinine kinase, aids

\section{Introduction}

Primary HIV infection (PHI) denotes the period of infection to seroconversion, during which rapid viral load accumulates, prompting viral antibodies from the host immune system [1]. Classically, seroconversion mimics a mononucleosis-like syndrome that occurs two to six weeks after exposure, but alternative presentations have been reported. Acute rhabdomyolysis is commonly caused by drug interactions, trauma, electrolyte derangements, toxins, and infections, releasing harmful contents into the bloodstream [2]. Infrequently, rhabdomyolysis has been associated with PHI, but few case reports describe it as the sole presentation of an acute infection. HIV-associated myopathy presenting with rhabdomyolysis and complicated by renal manifestation can have life-threatening presentations, requiring prompt recognition and initiation of antiretroviral therapy [3]. We report a patient whose sole presentation of PHI was rhabdomyolysis, but initial history taking and screening were inadequate. This case highlights the importance of diverse PHI presenting symptoms, obtaining an accurate history to identify sexually transmitted infections (STI), and the importance of gender-neutral sexual history tools to lessen delays in urgent antiretroviral therapy.

Review began 04/09/2021 Review ended 04/13/2021 Published 04/19/2021

\section{() Copyright 2021}

Ranabhat et al. This is an open access article distributed under the terms of the Creative Commons Attribution License CC-BY 4.0., which permits unrestricted use, distribution, and reproduction in any medium, provided the original author and source are credited.

\section{Case Presentation}

A previously healthy 21-year-old male presented with evolving nausea, vomiting, and abdominal pain over the preceding week. Initial workup at an urgent care was unremarkable for hepatitis, Epstein-Bar virus (EBV), and rapid HIV (antigen/antibody) $1 \& 2$, and no risk factors were identified. He was recommended conservative measures and sent home on close follow-up, however, his symptoms worsened to generalized weakness, cramping pains, fatigue, malaise, and fever, prompting a visit to the emergency department (ED) three days later. On arrival, he was hypotensive to $77 / 46 \mathrm{~mm} / \mathrm{hg}$, normocardic, afebrile, appearing weak and ill on physical exam. He was tender to palpation in both calves and muscle strength was $2-3 / 5$, and no accompanying neurological deficits were seen including sensory testing. Laboratory workup revealed leukopenia to 2.4K/UL, thrombocytopenia 91K/UL, creatinine kinase (CK) $9519 \mathrm{U} / \mathrm{L}$, lactate dehydrogenase $856 \mathrm{U} / \mathrm{L}$, and aldolase $39.4 \mathrm{U} / \mathrm{L}$. He has aggressively hydrated with lactated ringers. A subsequent reduction in CK levels was seen. A comprehensive workup was negative for infectious, autoimmune, or endocrine causes (Table 1). Keeping his age, presentation, and local rates, we strongly suspected HIV. The state of Michigan requires patient consent before testing, and after explaining our rationale, the patient provided consent. A 4th generation antigen and antibody test was positive with a polymerase chain reaction (PCR) assay growing 10,000,000 copies/ml, with positive HIV-1 seroconversion on a differentiation assay. Initial speciation of lymphocytes revealed a CD4 count of 195 cell/UL. Upon hearing the diagnosis, our patient admitted a bisexual history and that one of his partners had mentioned a possible HIV exposure in the past, although testing was never completed. An infectious disease consult recommended initiating bictegravir, emtricitabine, and tenofovir. His clinical course stabilized, and he was discharged on close follow-up. He had undetectable viral levels with a CD4 count of 673 cell/uL at his one-month follow-up and continued to have undetectable levels with a CD4 count of 617 cell/uL at his one-year follow-up. 


\section{Cureus}

Investigation

Result

Beta Hydroxy Butyrate

$<2 \mathrm{mg} / \mathrm{dL}$

Creatinine kinase (CK)

$9519 \mathrm{u} / \mathrm{L}$

Creatinine

$0.7 \mathrm{mg} / \mathrm{dl}$

Urinalysis

Blood +1, Protein +1 ,

yellow

Lactate

$1.9 \mathrm{mmol} / \mathrm{l}$

Aspartate Transaminase (AST)

719 U/L

Alanine Transaminase (ALT)

$346 \mathrm{U} / \mathrm{L}$

Haptoglobin

$29.3 \mathrm{mg} / \mathrm{dl}$

Beta Hydroxy Butyrate (b-OH)

$<2.0 \mathrm{mg} / \mathrm{dl}$

Thyroid Stimulating Hormone (TSH)

4.77 UIU/ML

Aldolase

$39.4 \mathrm{u} / \mathrm{l}$

Hepatitis panel - Hepatitis B surface antigen, Hepatitis B core antibody IgM, Hepatitis C antibody, and Hepatitis A IgM antibody

Negative

CMV IgM/lgG Ab EIA

Negative

EBV VCA Antibody panel

Negative

Syphilis

Non-reactive

Urine gonorrhea/chlamydia PCR

Negative

Blood cultures

No growth after 6 days

Cryptococcal antigen

Negative

Drug screen - opiates, marijuana, amphetamine, cocaine, benzodiazepines, ethanol, phencyclidine, methadone, and oxycodone

Negative

Salicylate/Acetaminophen levels

Negative

Antinuclear antibodies

Negative

Rheumatoid factor titer, Anti-Jo 1 lgG, and Anti-smooth muscle antibody

Negative

Plasma cortisol

$14 \mathrm{ug} / \mathrm{dl}$

ENA to Smith (sm) antibody, RNP antibody, SSA (Ro) antibody, SSB (La) antibody, and Antimitochondrial antibody

Negative

Erythrocyte sedimentation rate

$6 \mathrm{~mm} / \mathrm{hr}$

Lactate dehydrogenase

$856 \mathrm{u} / \mathrm{l}$

\section{TABLE 1: Laboratory investigations used}

CMV - Cytomegalovirus; EBV - Epstein-Barr virus; VCA - Viral capsid antigen; PCR: Polymerase chain reaction; ENA - Extractable nuclear antigen; RNP - Ribonucleic peptide

\section{Discussion}

$\mathrm{PHI}$ is a hyper-infectious state, and its prompt identification and treatment can prevent further transmission and reduce its inflammatory condition. With the appropriate sexual history and typical symptoms, suspicion for PHI can warrant pertinent testing. However, rhabdomyolysis is an exceedingly rare presentation of PHI, with an incidence rate of $0.943 \%$ [4]. Broadly, HIV myopathy can be classified as 1) HIV-associated rhabdomyolysis, 2) HIV therapy-induced rhabdomyolysis, and 3) opportunistic infection provoked myopathy in acquired immunodeficiency syndrome (AIDS), with the latter two more frequently reported. PHI 
presenting as rhabdomyolysis was first reported in 1989, and a literature review has been summarized in Table 2. A retrospective study demonstrated that lower viral loads were more consistent with anti-retroviralinduced myopathy. In our patient, HIV myopathy likely resulted from direct viral replication within the muscle leading to rhabdomyolysis and widespread fatigue [5]. Moreover, severe HIV presentation incited immunosuppression may predispose to acute myositis, as observed from our patient's AIDS defined CD4 count of 195 cell/UL [6]. Overall, HIV incidence has decreased, except in sexually active homosexual men, at approximately 10,000 infections among African American men who have sex with men (MSM), fitting our patient's demographic [7]. Advanced 4th generation HIV antigen and antibody combination assay is gradually replacing point-of-care rapid HIV testing as the primary diagnostic, as the latter has false negatives in the acute phase [2]. Nevertheless, up to $75 \%$ of PHI can remain undiagnosed due to the diversity of clinical presentation [8], demonstrating the importance of thorough sexual history taking or a high index of suspicion, similar to our patient encounter. HIV rhabdomyolysis is confirmed via CK elevation and the proper seroconversion findings. A biopsy is rarely required. The full extent of our patient's sexual history was elicited only after confirmatory combination assay testing. Physicians admitted a need for further education and training regarding sexual history taking [9]. Implementing a standardized, time-efficient, and gender-neutral sexual history-taking tool may mitigate stigma with at-risk populations. Moreover, in patients with appropriate risk factors, combination testing after a negative rapid HIV test may lessen the delays in viral detection and reduce lifetime HIV costs [10]. Physicians should utilize sexual history-taking tools in addition to staying vigilant of PHI in a patient with unanticipated muscle pains and elevated CK levels, especially in younger individuals.

\begin{tabular}{|c|c|c|c|c|c|c|c|c|c|c|c|c|c|}
\hline Author/Year & Age & Sex & $\begin{array}{l}\text { HIV+ } \\
\text { duration }\end{array}$ & $\begin{array}{l}\text { HIV } \\
\text { Stage }\end{array}$ & Viral Load & CD4 & SCrt & CK & Lactate & AST & ALT & $\begin{array}{l}\text { F/U } \\
\text { CPK }\end{array}$ & Outcome \\
\hline Prabahar et al., 2008 [11] & 42 & $M$ & New Dx & Acute & 638,000 & 436 & 6.8 & 278,000 & N/A & 3,640 & 419 & 623 & Recovery \\
\hline Ferrada et al., 2015 [12] & 19 & $\mathrm{M}$ & New Dx & Acute & 463,331 & 436 & 8.3 & 4,000 & N/A & N/A & N/A & 4,000 & Recovery \\
\hline Mahe et al., 1989 [13] & 18 & $M$ & New Dx & Acute & N/A & 304 & 1.3 & 5,750 & 882 & 165 & N/A & 106 & Recovery \\
\hline Babiker et al., 2015 [14] & 61 & $M$ & New Dx & Acute & 606,183 & 200 & 0.8 & 10,055 & N/A & 644 & 1,121 & 150 & Recovery \\
\hline $\begin{array}{l}\text { Hernandez-Munoz et al., } \\
2013 \text { [15] }\end{array}$ & 51 & $M$ & New Dx & Acute & 150,000 & N/A & 13.0 & 104,000 & N/A & $\uparrow$ & $\uparrow$ & N/A & N/A \\
\hline Neves et al., 1991 [16] & 24 & $\mathrm{~F}$ & New Dx & Acute & N/A & N/A & 0.5 & 2,359 & $\uparrow$ & N/A & N/A & N/A & Recovery \\
\hline Guillaume et al., 1995 [6] & 42 & $M$ & New $D x$ & Acute & N/A & N/A & 1.9 & 63,800 & 2820 & 1,480 & 461 & N/A & Recovery \\
\hline Rastegar et al., 2001 [17] & 51 & $\mathrm{M}$ & New Dx & Acute & 750,000 & 515 & 1.6 & 32,720 & N/A & 875 & 236 & 2,700 & Recovery \\
\hline $\begin{array}{l}\text { McDonagh and Holman, } \\
2003 \text { [18] }\end{array}$ & 33 & $\mathrm{M}$ & New Dx & Acute & 750,000 & N/A & 0.8 & 18,840 & N/A & 321 & 98 & N/A & Recovery \\
\hline Delo et al., 2006 [2] & 46 & $M$ & New Dx & Acute & 750,000 & N/A & 0.8 & 4,718 & N/A & 122 & 40 & 1,891 & Recovery \\
\hline $\begin{array}{l}\text { Pano-Pardo et al., } 2008 \\
\text { [19] }\end{array}$ & 19 & $\mathrm{~F}$ & New Dx & Acute & 100,000 & 264 & 2.3 & 10,681 & N/A & 153 & 103 & N/A & Recovery \\
\hline $\begin{array}{l}\text { Douvoyiannis and Litman, } \\
2009 \text { [1] }\end{array}$ & 20 & $\mathrm{M}$ & New Dx & Acute & 500,000 & 140 & 1.6 & 2,968 & N/A & 266 & 254 & $\mathrm{~N} / \mathrm{A}$ & Recovery \\
\hline Halperin et al., 2012 [8] & 33 & $\mathrm{~F}$ & New Dx & Acute & $1,500,000$ & 410 & N/A & 36,725 & N/A & N/A & N/A & N/A & Recovery \\
\hline Bhargava et al., 2016 [3] & 49 & $\mathrm{~F}$ & New Dx & Acute & 172,828 & 13 & 6.7 & 54,275 & N/A & N/A & N/A & N/A & Recovery \\
\hline Haddiya et al., 2016 [20] & 45 & $M$ & New Dx & Acute & $\mathrm{N} / \mathrm{A}$ & 200 & 2.0 & 1,900 & N/A & N/A & N/A & N/A & Death \\
\hline Noe et al., 2018 [5] & 24 & $M$ & New Dx & Acute & $10,000,000$ & 170 & 5.7 & 200,000 & N/A & N/A & N/A & N/A & Recovery \\
\hline
\end{tabular}

TABLE 2: Previously published case reports of rhabdomyolysis as the singular manifestation of primary HIV (PHI)

Age in years; HIViral load in copies/mL; CD4 in cells/uL; Creatinine in mg/dL; Lactate in U/L; AST and ALT in U/L

Dx: Diagnosis; N/A: Not applicable; CK: Creatinine kinase; SCrt: Serum Creatinine; F/U: Follow-up; AST: Aspartate transaminase; ALT: Alanine transaminase; CPK: Creatinine phosphokinase; $\uparrow:$ Increased. 


\section{Conclusions}

Primary HIV infection (PHI) has a wide range of clinical presentations; clinicians should be attentive to rhabdomyolysis as a lone manifestation. This allows for prompt treatment and counseling. The employment of a standardized sexual history-taking tool can curtail stigma in vulnerable patients lowering the number of undiagnosed individuals in the community. Strong clinical suspicion justifies combination assay testing immediately after rapid HIV screening, decreasing delays in diagnosis and treatment.

\section{Additional Information \\ Disclosures}

Human subjects: Consent was obtained or waived by all participants in this study. Conflicts of interest: In compliance with the ICMJE uniform disclosure form, all authors declare the following: Payment/services info: All authors have declared that no financial support was received from any organization for the submitted work. Financial relationships: All authors have declared that they have no financial relationships at present or within the previous three years with any organizations that might have an interest in the submitted work. Other relationships: All authors have declared that there are no other relationships or activities that could appear to have influenced the submitted work.

\section{References}

1. Douvoyiannis M, Litman N: Acute encephalopathy and multi-organ involvement with rhabdomyolysis during primary HIV infection. Int J Infect Dis. 2009, 13:299-304. 10.1016/j.ijid.2009.01.005

2. Delo D, Brett AS, Postic B: Primary HIV infection presenting with acute rhabdomyolysis. Am J Med Sci. 2006, 332:46-47. 10.1097/00000441-200607000-00010

3. Bhargava R, Abohashem Aly AA, Mertz JI, Mustafa R: Rhabdomyolysis as the first manifestation of human immunodeficiency virus infection. CEN Case Rep. 2016, 5:48-50. 10.1007/s13730-015-0189-7

4. Koubar SH, Estrella MM, Warrier R, Moore RD, Lucas GM, Atta MG, Fine DM: Rhabdomyolysis in an HIV cohort: epidemiology, causes and outcomes. BMC Nephrol. 2017, 18:242. 10.1186/s12882-017-0656-9

5. Noe MM, Jain AG, Shahid S, Majeed U: Severe rhabdomyolysis as an unusual presentation of primary human immunodeficiency virus infection. Cureus. 2018, 10:e3041. 10.7759/cureus.3041

6. Guillaume MP, Van Beers D, Delforge ML, Devriendt J, Cogan E: Primary human immunodeficiency virus infection presenting as myopericarditis and rhabdomyolysis. Clin Infect Dis. 1995, 21:451-452. 10.1093/clinids/21.2.451

7. Singh S, Song R, Johnson AS, McCray E, Hall HI: HIV incidence, prevalence, and undiagnosed infections in U.S. men who have sex with men. Ann Intern Med. 2018, 168:685-694. 10.7326/M17-2082

8. Halperin J, Richey LE, Mushatt D: The modern day masquerader: a rare case of acute HIV infection with neurologic complications and a review of the literature. J La State Med Soc. 2012, 164:76-80.

9. Lanier Y, Castellanos T, Barrow RY, Jordan WC, Caine V, Sutton MY: Brief sexual histories and routine HIV/STD testing by medical providers. AIDS Patient Care STDs. 2014, 28:113-120. 10.1089/apc.2013.0328

10. Schackman BR, Fleishman JA, Su AE, et al.: The lifetime medical cost savings from preventing HIV in the United States. Med Care. 2015, 53:293-301. 10.1097/MLR.0000000000000308

11. Prabahar MR, Jain M, Chandrasekaran V, Indhumathi E, Soundararajan P: Primary HIV infection presenting as non-traumatic rhabdomyolysis with acute renal failure. Saudi J Kidney Dis Transpl. 2008, 19:636-642.

12. Ferrada MA, Xie Y, Nuermberger E: Primary HIV infection presenting as limbic encephalitis and rhabdomyolysis. Int J STD AIDS. 2015, 26:835-836. 10.1177/0956462414560777

13. Mahé A, Bruet A, Chabin E, Fendler JP: Acute rhabdomyolysis coincident with primary HIV-1 infection . Lancet (British edition). 1989, 334:1454-1455. 10.1016/s0140-6736(89)92061-8

14. Babiker ZO, Wingfield T, Galloway J, Snowden N, Ustianowski A: Extreme elevation of ferritin and creatine kinase in primary infection with HIV-1. Int J STD AIDS. 2015, 26:68-71. 10.1177/0956462414531936

15. Hernandez-Munoz F, Dreilling S, Landry D, Besharatian B: HIV Induced Rhabdomyolysis. SGIM National Meeting, Denver; 2013.

16. Neves O, Stein CM, Thornton C, Gangaidzo I, Thomas JE: Rhabdomyolysis associated with human immunodeficiency virus (HIV) infection. Cent Afr J Med. 1991, 37:387-388.

17. Rastegar D, Claiborne C, Fleisher A, Matsumoto A: A patient with primary human immunodeficiency virus infection who presented with acute rhabdomyolysis. Clin Infect Dis. 2001, 32:502-504. 10.1086/318508

18. McDonagh CA, Holman RP: Primary human immunodeficiency virus type 1 infection in a patient with acute rhabdomyolysis. South Med J. 2003, 96:1027-1030. 10.1097/01.SMJ.0000077066.27020.9C

19. Paño-Pardo JR, Alcaide ML, Abbo L, Dickinson G: Primary HIV infection with multisystemic presentation. Int J Infect Dis. 2009, 13:177-180. 10.1016/j.ijid.2008.09.010

20. Haddiya I, Berkhli H, Hamaz S, Bentata Y: Adrenal insufficiency and mild rhabdomyolysis revealing a human immunodeficiency virus infection: a case report. Saudi J Med Med Sci. 2016, 4:212-214. 10.4103/1658-631X.188262 